\title{
High-yield production of aromatic peroxygenase by the agaric fungus Marasmius rotula
}

Glenn Gröbe ${ }^{1 *}$, René Ullrich², Marek J Pecyna², Danuta Kapturska ${ }^{3}$, Stephanie Friedrich', Martin Hofrichter ${ }^{2}$ and Katrin Scheibner ${ }^{4}$

\begin{abstract}
An extracellular peroxygenase from Marasmius rotula was produced in liquid culture, chromatographically purified and partially characterized. This is the third aromatic peroxygenase (APO) that has been characterized in detail and the first one that can be produced in high yields. The highest enzyme levels of about 41,000 $\mathrm{Ul}^{-1}$ (corresponding to appr. $445 \mathrm{mg} \mathrm{l}^{-1}$ APO protein) exceeded the hitherto reported levels more than 40-fold and were detected in carbon- and nitrogen-rich complex media. The enzyme was purified by FPLC to apparent homogeneity (SDS-PAGE) with a molecular mass of $32 \mathrm{kDa}$ (27 kDa after deglycosylation) and isoelectric points between 4.97 and 5.27. The UV-visible spectrum of the native enzyme showed a characteristic maximum (Soret band) at $418 \mathrm{~nm}$ that shifted after reduction with sodium dithionite and flushing with carbon monoxide to $443 \mathrm{~nm}$. The $\mathrm{pH}$ optimum of the $M$. rotula enzyme was found to vary between $\mathrm{pH} 5$ and 6 for most reactions studied. The apparent $K_{m}$-values for 2,6dimethoxyphenol, benzyl alcohol, veratryl alcohol, naphthalene and $\mathrm{H} 2 \mathrm{O} 2$ were $0.133,0.118,0.279,0.791$ and 3.14 $\mathrm{mM}$, respectively. M. rotula APO was found to be highly stable in a pH range from 5 to 10 as well as in the presence of organic solvents (50\% vol/vol) such as methanol, acetonitrile and $\mathrm{N}, \mathrm{N}$-dimethylformamide. Unlike other APOs, the peroxygenase of $M$. rotula showed neither brominating nor chlorinating activities.
\end{abstract}

Keywords: Peroxidase, Basidiomycota, Cytochrome P450, Bioreactor

\section{Introduction}

Enzymes catalyzing oxygen-transfer reactions are of great interest for chemical synthesis since they work selectively and under ambient conditions (Joo et al. 1999,). Despite this fact, production of respective biocatalysts is still limited to small scale in the laboratory and the few enzymes available are just provided as expensive fine chemicals. One reason for this is the intracellular nature of oxygenases, which is connected with complex cofactor requirements and low enzyme stability (Urlacher and Eiben 2006,). Thus cytochrome P450 monooxygenases (P450s), which represent the most versatile group of oxygen-transferring biocatalysts, need NAD(P) $\mathrm{H}$ as electron donating co-substrate and - at least - one accessory protein, a flavin reductase, as electron-transferring partner enzyme (Smith et al. 1994,). Most P450s

\footnotetext{
* Correspondence: ggroebe@hs-lausitz.de

'Department of Biology, Chemistry and Process Technology, Lausitz University of Applied Sciences, Großenhainer Straße 57, 01968 Senftenberg, Germany
}

Full list of author information is available at the end of the article tend to lose their activity rapidly outside the protecting cell, which hampers their purification and use in cellfree reaction systems (Urlacher et al. 2004,). Extracellular biocatalysts of the heme peroxidase type could help to overcome this problem, since they are secretory proteins and hence relatively stable, they have the same prosthetic group (protoporphyrine IX = heme) as P450s and form similar activated oxo-intermediates (compound I) (Pickard et al. 1991,, McCarthy and White 1983).

In 2004, an extracellular heme-thiolate peroxidase that fulfills these criteria was discovered in the agaric fungus Agrocybe aegerita (Ullich et al. 2004). The enzyme, first described as a haloperoxidase and nowadays mostly referred to as aromatic peroxygenase (APO) or unspecific peroxygenase (EC 1.11.2.1; http://www.chem.qmul.ac. uk/iubmb/enzyme/newenz.html), turned out to be a functional hybrid that shares catalytic properties with peroxidases and monooxygenases (Hofrichter and Ullrich 2006,, Hofrichter et al. 2010,). With hydrogen peroxide as co-substrate, the enzyme is capable of 
oxygenating various substrates, among others aromatic rings and alkyl substituents (Ullrich and Hofrichter 2005,, Kluge et al. 2007,, Aranda et al. 2009,), and it cleaves a variety of ethers (Kinne et al. 2009). This direct incorporation of oxygen from $\mathrm{H}_{2} \mathrm{O}_{2}$ can be described as peroxygenation and resembles the so-called peroxide "shunt" known as a side activity of some P450s (Joo et al. 1999).

A second extracellular APO with somewhat different catalytic properties was described for the Ink cap mushroom Coprinellus radians (Anh et al. 2007,, Aranda et al. 2009,, Aranda et al. 2010,). Furthermore, various homologous gene sequences and transcripts of putative peroxygenases have been identified in the course of searches in gene databases (Pecyna et al. 2009,, Hofrichter et al. 2010).

Using soybean suspensions as growth substrate, moderate amounts (5-10 $\mathrm{mg} \mathrm{L}^{-1}$ ) of $A$. aegerita APO (AaeAPO) and C. radians APO (CraAPO) can be produced in stirred-tank bioreactors and agitated culture flasks (Ullrich et al. 2004,, Anh et al. 2007). High-yield production of wild-type APOs, however, is so far not possible. Therefore, the aim of the present study has been to establish a procedure for the production of high amounts of APO using a novel production organism.

\section{Material and Methods \\ Organism}

Marasmius rotula [Scop.] Fr. (Pinwheel mushroom) (deposited at the German collection of microorganisms and cell cultures-DSMZ, collection number DSM 25031) was isolated from fruiting bodies that had developed on a meadow near Senftenberg (Germany) containing subsurface woody debris of Rubinia pseudoacacia (False Acacia). To confirm the strain affiliation to $M$. rotula at molecular level, the complete internal transcribed spacer (ITS) region including the 5.8S rRNA sequence of the ribosomal DNA was analyzed. For this, the isolated culture was grown on agar containing $1 \%$ malt extract and $0.5 \%$ glucose. Thereafter, genomic DNA was extracted from $100 \mathrm{mg}$ homogenized fungal mycelium using the DNeasy Plant Mini Kit (Qiagen $\mathrm{GmbH}$, Hilden, Germany) according to the manufacturer's protocol. PCR amplification of genomic DNA was performed in a total volume of $20 \mu$ l containing 2 $\mu \mathrm{l}$ template, $9 \mu \mathrm{l}$ GoTaq Green Master Mix, and $0.4 \mu \mathrm{l}$ 25 pmol of each of two general fungal ITS-rDNA primers ITS1 and ITS4 (White et al. 1990,) using standard cycling conditions. The direct sequencing of resulting 777 bp amplicon cleaned with ExoSAP-IT (USB Europe GmbH, Staufen, Germany) was performed on an ABI PRISM $3730 \times 1$ Genetic Analyzer (Applied Biosystems, Darmstadt, Germany) using the Big Dye Terminator v.3.1 Cycle Sequencing Kit (Applied Biosystems). The quality of the obtained sequence was checked by visual inspection of the electropherogram using a Sequence Scanner v.1.0 (Applied Biosystems) and edited using BioEdit v.7.0.9 (Hall 1999,). A nucleotide BLAST search at GenBank database (Zhang et al. 2000) in September 2011 revealed several hundred homologous sequences from Marasmius and related genera. However, only two sequences in the database reply showed a high query coverage (representing more than 700 aligned nucleotides) and a sequence identity higher than 95\%: an unnamed Marasmius species (accession number DQ449983, 709 aligned nucleotides, 99\% sequence identity) and the only known ITS sequence in GenBank of $M$. rotula (accession number DQ182506, 701 aligned nucleotides, $98 \%$ sequence identity) provided by the AFTOL project (Assembling the fungal tree of life; Celio et al. 2006). The ITS sequence of $M$. rotula strain DSM 25031 was submitted to GenBank database (accession number JN714927).

\section{Culture conditions}

Fungal stock cultures were grown in culture slants on $2 \%$ malt extract agar at $24^{\circ} \mathrm{C}$ and stored at $4^{\circ} \mathrm{C}$ in the dark. The content of one slant was homogenized in $40 \mathrm{ml}$ sterile sodium chloride solution $(0.9 \%)$ and used for the inoculation of liquid cultures $(5 \% \mathrm{vol} / \mathrm{vol}$ of the mycelium suspension). The carbon- and nitrogen-rich basic liquid medium contained $28 \mathrm{~g} \mathrm{~L}^{-1}$ glucose; $12 \mathrm{~g} \mathrm{~L}^{-1}$ peptone from soybean (Roth, Karlsruhe, Germany) and $3 \mathrm{~g} \mathrm{~L}^{-1}$ yeast extract (Merck, Darmstadt, Germany) dissolved in distilled water (Ikehata et al. 2004). Enzyme production was performed in 500-mL Erlenmeyer flasks containing $200 \mathrm{~mL}$ of the liquid medium. Cultivation occurred on a rotary shaker $(120 \mathrm{rpm})$ at $24^{\circ} \mathrm{C}$ for three to four weeks. Peroxygenase activity was measured every 1 to 3 days.

$M$. rotula was also cultivated in 5-L stirred-tank bioreactors (Sartorius, Melsungen, Germany) to produce larger amounts of peroxygenase. The medium (4 L) was the same as above and inoculation occurred with 200 $\mathrm{ml}$ mycelial suspension (fermentation parameters: $24^{\circ} \mathrm{C}$, stirring at $300 \mathrm{rpm}$ and $100 \%$ dissolved oxygen without $\mathrm{pH}$-regulation).

\section{Enzyme assays}

Peroxygenase activity was routinely measured by following the oxidation of veratryl alcohol into veratraldehyde ( $\varepsilon_{310}: 9,300 \mathrm{M}^{-1} \mathrm{~cm}^{-1}$ ) in McIlvaine buffer at $\mathrm{pH} 5.5$ (Ullrich et al. 2004). Reaction was started by addition of $2 \mathrm{mM} \mathrm{H}_{2} \mathrm{O}_{2}$. Laccase activity in the culture liquid and during the purification was detected by the oxidation of ABTS in McIlvaine buffer at pH 4.5 in the absence of $\mathrm{H}_{2} \mathrm{O}_{2}$ (Majcherczyk et al. 1999).

Further activities of purified $M$. rotula aromatic peroxygenase (MroAPO) were measured with benzyl alcohol, 
2,6-dimethoxyphenol (DMP) and ABTS under identical conditions by monitoring the formation of benzaldehyde $\left(\varepsilon_{280}: 1,400 \mathrm{~cm}^{-1} \mathrm{M}^{-1}\right)$, dimeric DMP quinone $\left(\varepsilon_{469}\right.$ : $\left.49,600 \mathrm{M}^{-1} \mathrm{~cm}^{-1}\right)$ and the ABTS cation radical $\left(\varepsilon_{420}\right.$ : $36,000 \mathrm{M}^{-1} \mathrm{~cm}^{-1}$ ) (Ullrich et al. 2004). Ring-hydroxylating activity of MroAPO was determined by the peroxygenation of naphthalene to 1-naphthol $\left(\varepsilon_{303}: 2,030 \mathrm{M}^{-1}\right.$ $\left.\mathrm{cm}^{-1}\right)$. The assay mixture contained in a total of $2 \mathrm{ml}: 1$ $\mathrm{ml}$ sodium phosphate/citrate buffer (100 mM pH 5.5), $200 \mu \mathrm{l}$ naphthalene $(5 \mathrm{mM})$ dissolved in $100 \%$ acetonitrile and 10 to $100 \mu$ l enzyme solution. The reaction was started with $20 \mu \mathrm{l} \mathrm{H}_{2} \mathrm{O}_{2}(200 \mu \mathrm{M})$ (Kluge et al. 2007).

\section{Enzyme purification}

The culture liquid of $M$. rotula was separated from the mycelium by filtration through paper filters (GF8, Whatman $\mathrm{GmbH}$, Dassel, Germany). The filtrate was frozen at $-80^{\circ} \mathrm{C}$ and then re-thawed to precipitate and remove extracellular glucans. After thawing, the culture liquid was filtrated through glass fiber filters (GF 8, Whatman).

The filtrate was concentrated 40 -fold by two steps of ultrafiltration using two tangential-flow cassettes (Sartocon Slice Cassette, Hydrosart, cut-off $10 \mathrm{kDa}$, Sartorius, and Omega membrane, cut-off $10 \mathrm{kDa}$, Pall Life Sciences, Dreieich, Germany). All subsequent chromatographic purification steps were performed with an Äkta FPLCTMSystem (GE Healthcare Europe GmbH, Freiburg, Germany). In the first step, the crude preparation was loaded onto a Q Sepharose FF column (anion exchanger XK 26/20, GE Healthcare) and the proteins were eluted with a linear gradient of $0-0.7 \mathrm{M} \mathrm{NaCl}$ in $10 \mathrm{mM}$ sodium acetate buffer ( $\mathrm{pH} 5.5)$ at a flow rate of $6 \mathrm{ml}$ $\mathrm{min}^{-1}$. MroAPO containing fractions were pooled, concentrated and dialyzed against $10 \mathrm{mM}$ sodium acetate ( $\mathrm{pH}$ 5.5, $10 \mathrm{kDa}$ cut-off Omega membrane, Pall Life Sciences). Pooled fractions were subjected to a second anion exchanger consisting of mono beads (Mono Q $10 / 100$, GE Healthcare) and using sodium acetate (10 $\mathrm{mM}, \mathrm{pH} 5.5$ ) and an increasing gradient up to $0.4 \mathrm{M}$ sodium chloride for elution. MroAPO containing fractions were pooled, concentrated and dialyzed against 10 $\mathrm{mM}$ sodium acetate. In the next step, an anion exchanger consisting of Source 15Q (10/10, GE Healthcare) was used along with sodium acetate (25 mM, pH 5.0) and an increasing gradient up to $0.4 \mathrm{M}$ sodium sulphate for elution. MroAPO containing fractions were pooled, concentrated and dialyzed against $50 \mathrm{mM}$ sodium phosphate buffer (pH 8.0, 10 kDa cut-off Vivaspin 20, Satorius Stedim Biotech GmbH, Goettingen, Germany). Afterwards, size exclusion chromatography (SEC; Superdex 75 16/60, GE Healthcare) was carried out under isocratic conditions in $50 \mathrm{mM}$ sodium phosphate $(\mathrm{pH} 8.0$, $+0.15 \mathrm{M}$ sodium chloride). The pooled and concentrated
MroAPO fractions were re-chromatographed on a Mono Q column (5/50, GE Healthcare) using sodium acetate (10 mM, pH 5.5) and an increasing gradient up to 0.25 M sodium chloride for elution. MroAPO containing fractions were eventually pooled, concentrated and dialyzed against $50 \mathrm{mM}$ sodium phosphate buffer ( $\mathrm{pH} 8.0$, $10 \mathrm{kDa}$ cut-off Vivaspin 20) and stored at $4^{\circ} \mathrm{C}$. During early FPLC-separation steps (e.g. first Mono-Q separation), the elution profiles showed up to four heme peaks with veratryl alcohol oxidizing activity; we focused our purification efforts always on the most active fraction (i. e. that with the highest specific activity).

\section{Characterization of MroAPO}

Molecular mass of purified MroAPO was determined by sodium dodecyl sulfate-polyacrylamide gel electrophoresis (SDS-PAGE) using a $12.5 \%$ NuPage Novex Bis-Tris Gel (Invitrogen, Darmstadt, Germany). A low-molecular mass protein calibration kit (MBI Fermentas, PageRuler ${ }^{\mathrm{TM}}$, Roth, Germany) was used as standard. Isoelectric focusing (IEF) was carried out using precast gels ( $\mathrm{pH} 3-$ 7; Invitrogen) and specific IEF markers ( $\mathrm{pH} 3-10$; Serva, Heidelberg, Germany) as standard. Electrophoretically separated protein bands were visualized with the Colloidal Blue staining kit (Invitrogen).

Purified MroAPO $(75 \mu \mathrm{g})$ was denaturated with SDS and deglycosylated for 4 hours with the Enzymatic Protein Deglycosylation Kit from Sigma (Saint Louis, MO, USA). The latter contained PNGase F, O-glycosidase, two $\alpha-2(3,6,8,9)$ neuramidases as well as $\beta-1,4$-galactosidase and $\beta-N$-acetylglucosaminidase and was used according to the instructions of the provider. Molecular mass of the deglycosylated protein was determined by SDS-PAGE using a $12 \%$ NuPAGE Novex Bis-Tris Gel (Invitrogen).

Apparent Michaelis-Menten $\left(\mathrm{K}_{\mathrm{m}}\right)$ and catalytic $\left(\mathrm{k}_{\mathrm{cat}}\right)$ constants of purified MroAPO were determined at $\mathrm{pH}$ 5.5 for veratryl alcohol, benzyl alcohol, DMP, ABTS, naphthalene, and $\mathrm{H} 2 \mathrm{O} 2$. Lineweaver-Burk plots were prepared from the initial rates obtained with various substrate concentrations while the concentration of the second substrate was kept constant.

Stability of MroAPO in organic solvents was tested by incubating the enzyme $(1 \mathrm{U}=0.31 \mu \mathrm{M})$ in aqueous buffer mixtures (vol/vol) of methanol, acetonitrile and $N, N$ dimethylforamide (DMF). Organic solvent concetrations of 10, 30, 50 and $70 \%$ were used. All mixtures were kept at $24^{\circ} \mathrm{C}$ for up to $120 \mathrm{~min}$. For determination of the remaining enzyme activity, samples were taken after 1 , 30,60 and $120 \mathrm{~min}$ and measured using the veratryl alcohol assay mentioned above.

The UV-Vis spectrum of the resting-state MroAPO was recorded in $10 \mathrm{mM}$ sodium acetate buffer ( $\mathrm{pH} 5.5$ ) in the range from 200 to $700 \mathrm{~nm}$ using a Cary 50 
spectrophotometer (Varian, Darmstadt, Germany). To obtain the reduced $\mathrm{CO}$-enzyme complex, samples were reduced with sodium dithionite and flushed with carbon monoxide for $2 \mathrm{~min}$.

For N-terminal analysis, MroAPO was separated by SDS-PAGE as described above and transferred from the SDS gel to a polyvinylidene fluoride membrane (Amersham Biosciences, Freiburg, Germany) by electroblotting. Sequencing by Edman degradation and de-novo-peptide sequencing using matrix-assisted laser desorption/ionization mass spectrometry (MALDI-TOF/TOF) after digestion with trypsin were performed by Protagen AG (Dortmund, Germany). Sequences were compared with known APOs (A. aegerita, C. radians) and chloroperoxidase (CPO; Caldariomyces fumago) as well as with putative APO- and CPO-like sequences from the National Center for Biotechnology Information (NCBI) GenBank database by using BLASTp.

\section{Further substrate oxidation studies}

Enzymatic conversion of toluene was performed in 2$\mathrm{mL}$ reaction vials containing citrate phosphate buffer ( $\mathrm{pH} 5.5), 1 \mathrm{mM}$ toluene, and $10 \mathrm{U}$ MroAPO $(3.1 \mu \mathrm{M})$. The reaction was started by addition of H2O2 (2 mM), which was repeated four times in 2.5 min steps.

For naphthalene oxidation, two reaction solutions were prepared. Solution A contained 2 U MroAPO $(0.62$ $\mu \mathrm{M}$ ) in $1 \mathrm{~mL}$ citrate phosphate buffer ( $\mathrm{pH} 5.5$ ) and solution B consisted of $2 \mathrm{mM}$ naphthalene and $2 \mathrm{mM} \mathrm{H} 2 \mathrm{O} 2$ in $1 \mathrm{~mL} \mathrm{50 \%} \mathrm{(vol/vol)} \mathrm{acetonitrile.} \mathrm{Every} 2.5 \mathrm{~min}, 250$ $\mu \mathrm{L}$ of solution B were transferred to solution A. After $10 \mathrm{~min}$, reactions were stopped by addition of $20 \mu \mathrm{l} \mathrm{HCl}$ (37\%).

Reaction products were analyzed by HPLC using an Agilent $^{\circledR} 1200$ system (Waldbronn, Germany) equipped with a diode array detector and a LiChrospher reversed phase (C18) column $(4.6 \times 125 \mathrm{~mm}, 5 \mu \mathrm{m}$; Phenomenex, Aschaffenburg, Germany). For toluene and its oxidation products, a gradient separation was applied from 15 to $80 \%$ acetonitrile (0-5 $\mathrm{min} ; 15 \%$; 5 - 25 min $15-80 \%$ ) in $20 \mathrm{mM}$ aqueous potassium dihydrogenphosphate buffer $(\mathrm{pH} 2.8)$ at a flow rate of $0.7 \mathrm{~mL} \mathrm{~min}^{-1}$. For naphthalene, a gradient from 20 to $80 \%$ acetonitrile (0-5 min; $20 \%$; $5-20 \mathrm{~min}$; $20-80 \%$ ) in $20 \mathrm{mM}$ potassium dihydrogen phosphate $(\mathrm{pH} 2.8)$ was used at a flow rate of $1 \mathrm{~mL}$ $\mathrm{min}^{-1}$. Eluted substances were recorded at $220 \mathrm{~nm}$ and identified/quantified by means of authentic standards.

Possible halogenating activity of MroAPO was tested as previously described (Ullrich and Hofrichter 2005). Briefly, the enzyme $(0.31 \mu \mathrm{M})$ was incubated in potassium phosphate buffer $(100 \mathrm{mM}, \mathrm{pH} 3)$ in the presence of phenol $(0.1 \mathrm{mM})$, potassium bromide or chloride (10 $\mathrm{mM}$ ) and $\mathrm{H}_{2} \mathrm{O}_{2}$. After $10 \mathrm{~min}$, the reaction mixture was analyzed by HPLC for the formation of bromo- and chlorophenols using authentic monohalophenols as standards. In a second test, the oxidation of bromide $\left(\mathrm{Br}^{-}\right)$and iodide $\left(\mathrm{I}^{-}\right)$into tribromide $\left(\mathrm{Br}_{3}{ }^{-}\right)$and respectively triodide $\left(\mathrm{I}_{3}{ }^{-}\right)$was spectrophotometrically followed (Libby et al. 1982).

\section{Chemicals}

2,2'-Azinobis-(3-ethylbenzothiazoline-6-sulfonate) (ABTS) was purchased from Applichem (Darmstadt, Germany), 2,6-dimethoxyphenol (DMP), naphthalene, 1napththol, 2-naphthol, potassium chloride and toluene from Sigma-Aldich (München, Germany). Veratryl alcohol, veratraldehyde, veratric acid, benzyl alcohol, benzaldehyde, benzoic acid, phenol, $\mathrm{H} 2 \mathrm{O} 2(30 \%$, w/v), sodium acetate, sodium chloride, sodium sulphate, methanol and acetonitrile were obtained from Roth (Steinheim, Germany). All other chemicals and solvents were purchased from Merck (Darmstadt, Germany).

\section{Results}

\section{Enzyme production}

A medium containing both glucose, peptone from soybean, and yeast extract was essential for the production of MroAPO. Increasing the amount of these components resulted in a considerable enhancement of enzyme activity. Their concentrations were varied from $100 \%$ to $400 \%$ and respectively $800 \%$, i.e. 14 to $56 \mathrm{~g} \mathrm{~L}^{-1}$ glucose, 6 to $48 \mathrm{~g} \mathrm{~L}^{-1}$ soybean peptone and 1.5 to $6 \mathrm{~g} \mathrm{~L}^{-1}$ yeast extract were tested (Figure 1). The maximum activity of MroAPO $\left(40,944 \mathrm{U} \mathrm{L}^{-1}\right.$, veratryl alcohol assay) was detected in the presence of $42 \mathrm{~g} \mathrm{~L}^{-1}$ glucose (300\%), 48 $\mathrm{g} \mathrm{L}^{-1}$ soybean peptone (700\%) and $4.5 \mathrm{~g} \mathrm{~L}^{-1}$ yeast extract (300\%) and later (after purification) found to correlate with roughly $445 \mathrm{mg} \mathrm{L}^{-1}$ peroxygenase protein. Figure 2 describes the time course of MroAPO activity and $\mathrm{pH}$ under these conditions. During the first days of cultivation, the pH increased slightly from 5.6 to 6.3 on day 8 . MroAPO activity appeared in the culture liquid 10 to 11 days after inoculation and within this phase, the $\mathrm{pH}$ decreased from $\mathrm{pH} 6.3$ to $\mathrm{pH} 5.7$ on day 12 and remained almost constant until day 21 (Figure 2). The maximum activity of MroAPO was detected on day 24 of cultivation, i.e. 3 to 4 days after the $\mathrm{pH}$ had started to increase again reaching a maximum value of 7.5 on day 25. Afterwards, both the enzyme activity and the $\mathrm{pH}$ slightly dropped $(\sim 10 \%)$ until the end of the experiment (day 28) (Figure 2). The fungal biomass consisting of whitish pellets (max. $3-5 \mathrm{~mm}$ in diameter) at this time was $25.8 \mathrm{~g} \mathrm{~L}^{-1}$ (dry mass). In addition to peroxygenase, also laccase activities were detected with a maximum of $5,992 \mathrm{U} \mathrm{L}^{-1}$ on day 15 (Figure 2).

To obtain larger amounts of MroAPO, M. rotula was cultured in 5-L stirred-tank bioreactors using the optimized medium mentioned above. Production of 


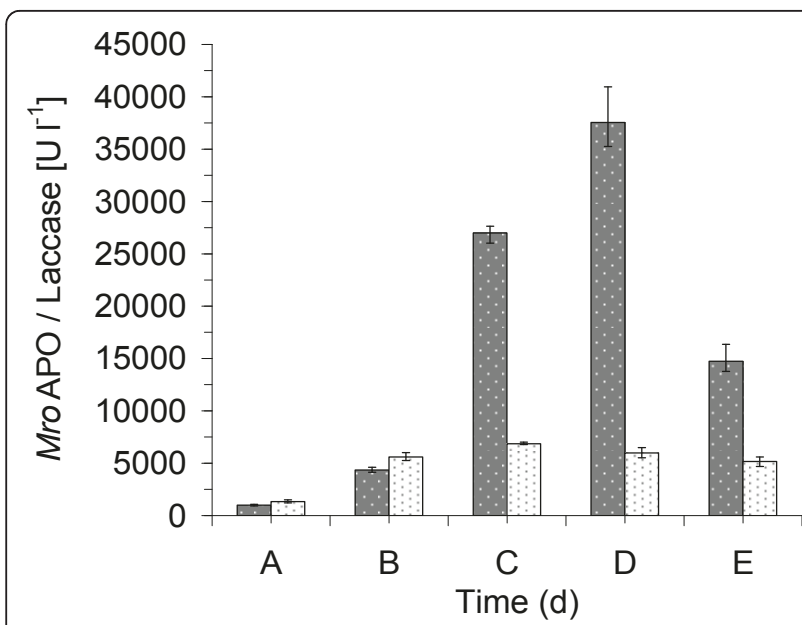

Figure 1 Effect of different combinations of glucose, soybean peptone and yeast extract on the production of MroAPO (grey columns with white dots) and laccase (white columns with black dots). A - glucose $\left(14 \mathrm{~g} \mathrm{~L}^{-1}\right)$, soybean peptone $\left(6 \mathrm{~g} \mathrm{~L}^{-1}\right)$, yeast extract $\left(1.5 \mathrm{~g} \mathrm{~L}^{-1}\right), \mathrm{B}$ - glucose $\left(28 \mathrm{~g} \mathrm{~L}^{-1}\right)$, soybean peptone $\left(12 \mathrm{~g} \mathrm{~L}^{-1}\right)$, yeast extract $\left(3 \mathrm{~g} \mathrm{~L}^{-1}\right), \mathrm{C}$ - glucose $\left(28 \mathrm{~g} \mathrm{~L}^{-1}\right)$, soybean peptone $\left(48 \mathrm{~g} \mathrm{~L}^{-1}\right)$, yeast extract $\left(3 \mathrm{~g} \mathrm{~L}^{-1}\right), \mathrm{D}$ - glucose $\left(42 \mathrm{~g} \mathrm{~L}^{-1}\right)$, soybean peptone (48 $\mathrm{g}$ $\left.\mathrm{L}^{-1}\right)$, yeast extract $\left(4.5 \mathrm{~g} \mathrm{~L}^{-1}\right), \mathrm{E}$ - glucose $\left(56 \mathrm{~g} \mathrm{~L}^{-1}\right)$, soybean peptone $\left(48 \mathrm{~g} \mathrm{~L}^{-1}\right)$, yeast extract $\left(6 \mathrm{~g} \mathrm{~L}^{-1}\right)$. Cultivation was carried out in 500$\mathrm{ml}$ flasks containing $200 \mathrm{ml}$ of the respective liquid medium. Flasks were shaken at $120 \mathrm{rpm}$ at $24^{\circ} \mathrm{C}$ in the dark for 28 days (data points represent maximum levels obtained within the cultivation period). MroAPO activity was measured with veratryl alcohol at pH 5.5 (modified according to Ullrich et al. 2004,). Laccase activity was measured with ABTS at pH 4.5 (Majcherczyk et al. 1999). Dry masses after 28 days: $\mathrm{A}-6.35 \mathrm{~g} \mathrm{~L}^{-1}, \mathrm{~B}-12.15 \mathrm{~g} \mathrm{~L}^{-1}, \mathrm{C}-17.5 \mathrm{~g} \mathrm{~L}^{-1}, \mathrm{D}-25.8 \mathrm{~g}$ $\mathrm{L}^{-1}$. $\mathrm{E}-15.5 \mathrm{~g} \mathrm{~L}^{-1}$. Values given are means of three parallel flasks with standard deviations.

MroAPO started on day 12 of fermentation and reached the maximum of $25,000 \mathrm{U} \mathrm{L}^{-1}\left(280 \mathrm{mg} \mathrm{L}^{-1}\right)$ on day 24 (data not shown); immediately afterwards, the culture liquid of the bioreactors was harvested and used for enzyme purification studies. The final biomass in the bioreactor was $45.4 \mathrm{~g} \mathrm{~L}^{-1}$.

\section{Purification and physical characterization of MroAPO}

The culture liquid was separated from the fungal mycelium by filtration, then frozen at $-80^{\circ} \mathrm{C}$, re-thawed and centrifuged to remove polysaccharides (Ullrich et al. 2004). A loss of enzyme activity was not caused by this procedure. Afterwards, the crude extract was concentrated by ultrafiltration and separated by five chromatographic steps using an FPLC system and strong anion exchangers (Q Sepharose FF, Mono Q 10/100, Source $15 \mathrm{Q}$, Mono Q 5/50 columns) as well as a molecular sieve (SEC Superdex column) (Table 1). Figures $3 \mathrm{~A}$ and 3B show the elution profiles of an early Mono-Q 10/100 separation with four pronounced peroxygenase peaks and the final purification step on a Mono Q 5/50 column with just one peroxygenase fraction. The specific

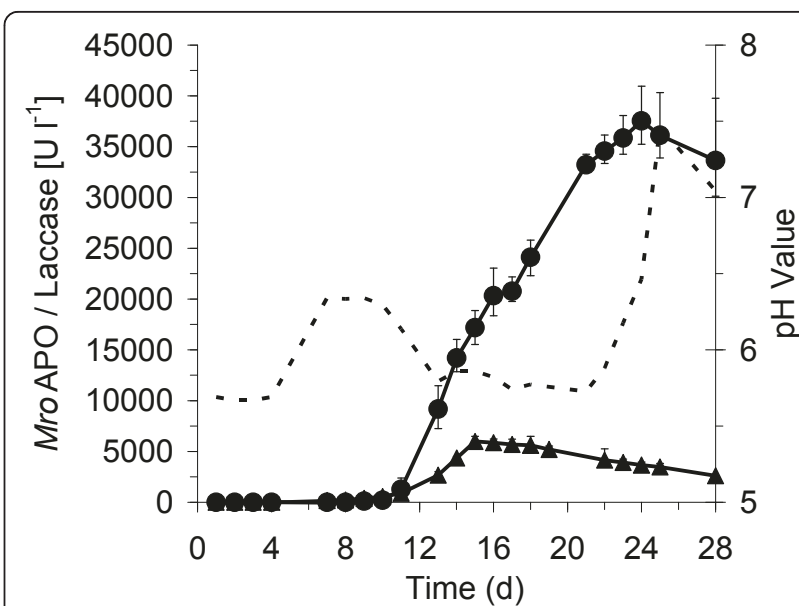

Figure 2 Time course of peroxygenase (circles) and laccase (triangles) production by agitated cultures of $M$. rotula under optimized conditions in a liquid medium consisting of $42 \mathrm{~g} \mathrm{~L}^{-1}$ glucose, $45 \mathrm{~g} \mathrm{~L}^{-1}$ soybean peptone and $4.5 \mathrm{~g} \mathrm{~L}^{-1}$ yeast extract. MroAPO activity was measured with veratryl alcohol at pH 5.5 and laccase activity with ABTS at pH 4.5. Data points represent mean values of three parallel culture flasks with standard deviations. The dotted line marks the time course of $\mathrm{pH}$.

activity of the latter was $77 \mathrm{U} \mathrm{mg}^{-1}$ (veratryl alcohol assay) and it was used for the physical and catalytic characterization of the protein.

SDS-PAGE revealed a molecular mass of $32 \mathrm{kDa}$ for the purified MroAPO protein and analytical isoelectric focusing gave three pI-bands between 4.97 and 5.27 (major band at 5.27; inset of Figure 3). The purified and re-chromatographed major isoform was deglycosylated to remove covalently bound carbohydrates. The deglycosylated protein had a molecular mass of $27 \mathrm{kDa}$, i.e. the carbohydrate content of the mature protein is 16\% (Figure 3).

The UV-visible spectrum of the resting state enzyme showed a characteristic absorbance at $418 \mathrm{~nm}$ (Soret band), two further maxima of at $570 \mathrm{~nm} 536 \mathrm{~nm}(\alpha-$ and $\beta$-bands) as well as a $\delta$-band at $353 \mathrm{~nm}$. After addition of sodium dithionite and flushing with $\mathrm{CO}$, the CO-complex of reduced MroAPO was formed. This was accompanied by a shift of the Soret band to $443 \mathrm{~nm}$, which is still in the characteristic range of heme-thiolate proteins (Figure 4). The spectral data of MroAPO in comparison to four other heme-thiolate proteins are given in Table 2.

The obtained N-terminal sequence of MroAPO (10 amino acids) showed $40 \%, 20 \%$ and $20 \%$ identity to the N-terminal sequences of AaeAPO, CraAPO and CfuCPO (Figure 5A). An additional NCBI database search with MS/MS data for tryptic peptides of purified MroAPO failed, and therefore de-novo peptide sequencing was performed (Figure 5B). The data obtained for an MroAPO peptide consisting of 12 amino acids show 
Table 1 Exemplary table for the purification of MroAPO by fast protein liquid chromatography (FPLC)

\begin{tabular}{|c|c|c|c|c|c|}
\hline Steps & $\begin{array}{c}\text { Total Activity } \\
\text { (Units) }\end{array}$ & $\begin{array}{l}\text { Total Protein } \\
(\mathrm{mg})\end{array}$ & $\begin{array}{c}\text { Specific Activity } \\
\left(\mathrm{U} \mathrm{mg}^{-1}\right)\end{array}$ & $\begin{array}{c}\text { Yield } \\
(\%)\end{array}$ & $\begin{array}{c}\text { Purification } \\
\text { (fold) }\end{array}$ \\
\hline Culture fluid & 11,700 & 730 & 16 & 100 & 1 \\
\hline Ultrafiltration step & 11,520 & 415 & 28 & 98 & 1.7 \\
\hline Q Sepharose FF & 10,413 & 218 & 48 & 89 & 3.0 \\
\hline Mono Q & 6,235 & 118 & 53 & 53 & 3.3 \\
\hline Source $15 \mathrm{Q}$ & 1,457 & 22 & 88 & 17 & 5.5 \\
\hline SEC & 768 & 9 & 90 & 7 & 5.6 \\
\hline Mono Q & 75 & 0.98 & 76 & 0.7 & 4.8 \\
\hline
\end{tabular}

Enzyme activities are based on the oxidation of veratryl alcohol to veratrylaldehyde at $\mathrm{pH} 5.5$. The purification processes started with $468 \mathrm{~mL}$ culture fluid from the bioreactor fermentation (volume activity $25 \mathrm{U} \mathrm{mL}^{-1}$ ) corresponding to a total of 11,700 Units.

$67 \%$ identity to the putative APO-like protein sequence of Moniliophthora perniciosa (gi 215458597) that is also a member of the family Marasmiaceae and closely related to the genus Marasmius (Kerekes and Desjardin 2009). However, the second de-novo peptide obtained (STTPITIPLLTTGIHR, $1720.97 \mathrm{Da}$ ) did not show any similarity to known fungal peroxidases/peroxygenases according to respective database searches.

\section{Oxidation of different substrates, influence of $\mathrm{pH}$ and kinetic parameters}

The $\mathrm{pH}$ dependence of MroAPO was studied using DMP, benzyl alcohol, veratryl alcohol, ABTS and naphthalene as substrates (Figure 6). All pH profiles have pronounced acidic maxima between 4.5 and 6 . Thus, the optimum of ABTS oxidation was found to be $\mathrm{pH} 4.5$, those of veratryl alcohol and DMP oxidation $\mathrm{pH}$ 5.5 and 5.0, respectively. The oxidation of benzyl alcohol showed two distinct maxima at $\mathrm{pH} 5$ and 6 . The optimum for the hydroxylation of naphthalene into 1naphthol (major product) was detected between $\mathrm{pH} 5.5$ and 6.0. All in all, MroAPO was active in a broad $\mathrm{pH}$ range between 2 and 9 .

Apparent Michealis-Menten $\left(\mathrm{K}_{\mathrm{m}}\right)$ and catalytic constants $\left(k_{\text {cat }}\right)$ as well as catalytic efficiencies $\left(k_{\text {cat }} / K_{m}\right)$ of all tested substrates are summarized in table 3. Under the conditions used, DMP and benzyl alcohol were the best substrates; veratryl alcohol and naphthalene were oxidized with 3- and 18-times lower catalytic efficiencies, respectively. While the turnover numbers for all substrates were roughly in the same order of magnitude (25 to $187 \mathrm{~s}^{-1}$ ), the $\mathrm{K}_{\mathrm{m}}$ values varied in one order of magnitude from $0.071 \mathrm{mM}$ (for ABTS) to $0.791 \mathrm{mM}$ (for naphthalene). Interestingly, the highest $\mathrm{K}_{\mathrm{m}}$ (3.14 $\mathrm{mM}$ ) was determined for $\mathrm{H}_{2} \mathrm{O}_{2}$ (with veratryl alcohol as substrate) indicating a relatively low affinity of the enzyme to its electron-accepting co-substrate.

Using 0.05-0.4 U (0.0155-0.124 $\mu \mathrm{M})$ of MroAPO, the optimum concentration of $\mathrm{H}_{2} \mathrm{O}_{2}$ for the oxidation of veratryl alcohol was found to be $4 \mathrm{mM}$; at a concentration of $2 \mathrm{mM}$ peroxide, the detected activity was by $15 \%$ lower. In case of benzyl alcohol and DMP oxidation, the optimum concentration of $\mathrm{H} 2 \mathrm{O} 2$ was over $10 \mathrm{mM}$ and $5 \mathrm{mM}$, respectively, indicating a rather high co-substrate requirement in these reactions and possibly a pseudocatalase activity that destroys/consumes $\mathrm{H}_{2} \mathrm{O}_{2}$ without contributing to the peroxygenase cycle. In contrast, the hydroxylation of naphthalene was optimal when a lower amount of $1 \mathrm{mM} \mathrm{H} 2 \mathrm{O} 2$ was used (data not shown).

The influence of organic solvents on the enzyme stability was determined in aqueous buffer mixtures at concentrations of $10,30,50$ and $70 \% \mathrm{vol} / \mathrm{vol}$ using the veratryl alcohol assay. In case of methanol, at least $80 \%$ of the initial activity was still found after 2 hours of incubation at all concentrations. A 2-hour incubation in the presence of 10 or $30 \%$ acetonitrile did not cause any decrease in MroAPO activity, while 50 and $70 \%$ acetonitrile caused an activity loss of 23 and 28\%, respectively. Concentrations of 10,30 or $50 \%$ DMF did not affect the activity of MroAPO but it decreased by more than $90 \%$ within the first $30 \mathrm{~min}$ of incubation at 70\% DMF.

\section{Further substrate oxidation studies}

To further characterize the oxygen transfer catalyzed by MroAPO, the product patterns and ratios of toluene and naphthalene oxidation were analyzed. Using toluene (1 $\mathrm{mM})$, the major oxidation product was benzoic acid $(0.896 \mathrm{mM})$, followed by benzaldehyde $(0.074 \mathrm{mM})$ and methyl-p-benzoquinone $(0.037 \mathrm{mM})$; the former two products were the result of side chain oxidation while the formation of the latter can only be explained by an initial hydroxylation in para-position to give $p$-cresol that in turn was oxidized into the corresponding $p$-benzoquinone derivative. On this basis, a ratio of side chain vs. ring hydroxylation of $26: 1$ can be inferred for toluene oxidation by MroAPO. Naphthalene $(1 \mathrm{mM})$ was regioselectively converted into 1-naphthol $(0.922 \mathrm{mM})$ and 2naphthol $(0.078 \mathrm{mM})$ as major and minor products, respectively (ratio 12:1).

MroAPO was neither capable of brominating nor chlorinating phenol in the presence of potassium bromide or respectively potassium chloride, i.e. no 


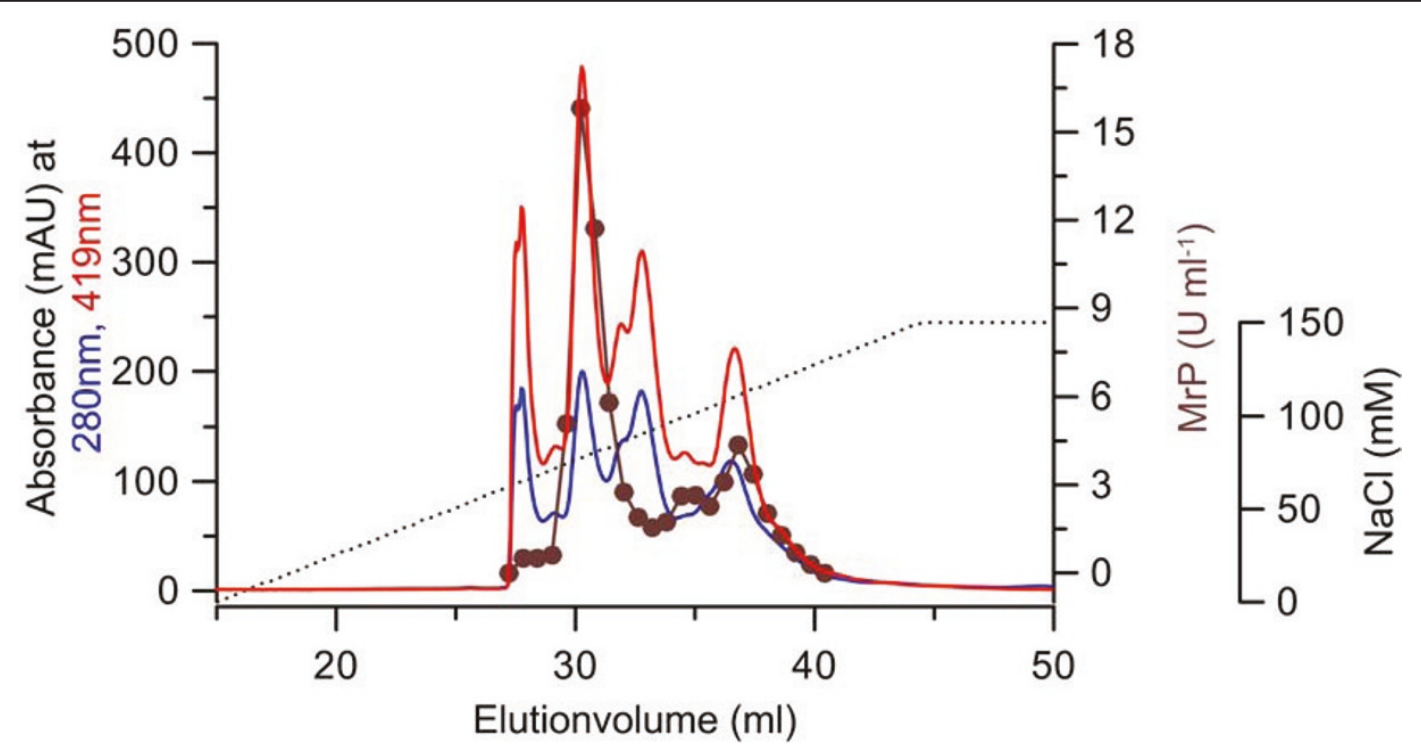

a

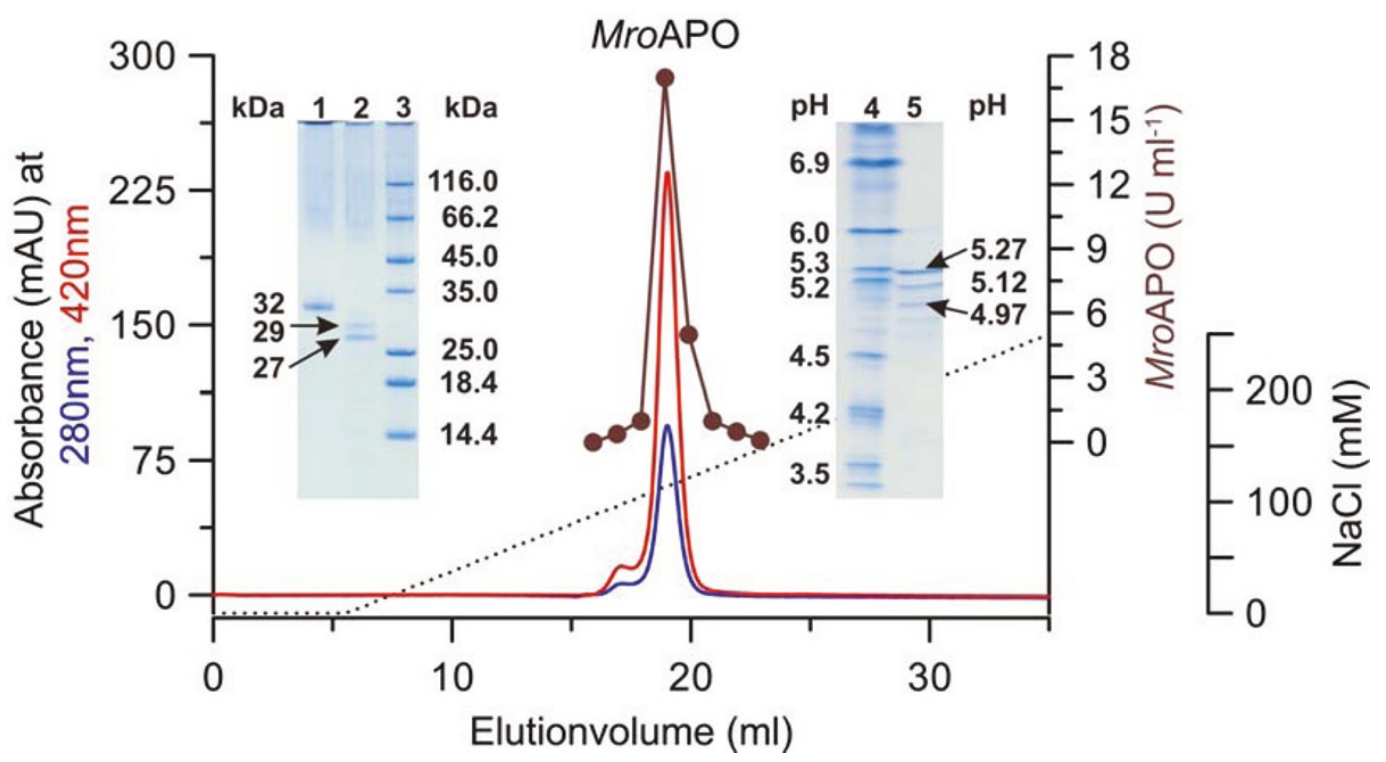

b

Figure 3 Purification of MroAPO by FPLC (Mono Q, steps two and five). (A) - Early FPLC separation step on a Mono Q column 10/100 column showing four major heme peaks with veratryl alcohol oxidizing activity (further purification focused on the second peak). (B) - FPLC elution profile of the final purification step of MroAPO performed on a Mono Q 5/50 column. Heme absorption at $420 \mathrm{~nm}$ (red line), total protein at $280 \mathrm{~nm}$ (blue line), $\mathrm{NaCl}$ gradient (dotted line). APO activity was detected by the oxidation of veratryl alcohol at pH 5.5. The insets show the respective SDS-PAGE (left) and isoelectric focusing gels (right). The second lane of the SDS-PAGE gel shows the molecular mass of the partially and fully deglycosylated MroAPO protein at 29 and $27 \mathrm{kDa}$, respectively.

bromo- or chlorophenol was detectable by HPLC. The assay was performed both at $\mathrm{pH} 3$ and $\mathrm{pH} 5.5$ and in the presence of different peroxide concentrations. Also the formation of tribromide, as the result of possible bromide oxidation, was not observed. Merely iodide was slowly oxidized into triiodide. These results indicate a weak halogenating activity of MroAPO that sets the enzyme apart from other fungal heme-thiolate peroxidases (CPO, AaeAPO) (Hofrichter and Ullrich 2006). 


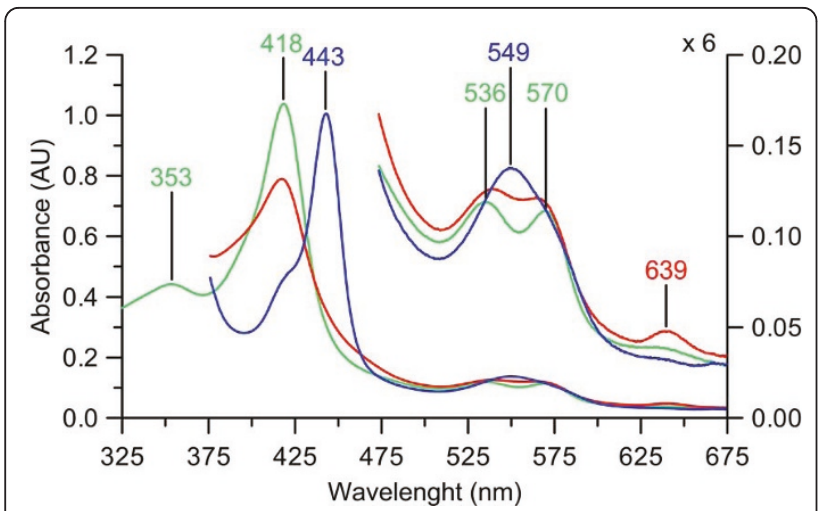

Figure 4 UV-Vis absorption spectra of purified MroAPO. Native MroAPO (green), MroAPO reduced with dithionite (red) and reduced CO-complex of MroAPO (blue).

\section{Discussion}

The agaric basidiomycete $M$. rotula produced a novel aromatic peroxygenase (MroAPO) during growth in agitated liquid culture. The enzyme was purified to apparent homogeneity and characterized. It is a relatively small $\left(\mathrm{M}_{\mathrm{w}}: 32 \mathrm{kDa}\right)$, glycosylated (16\%) heme-thiolate protein that peroxygenates naphthalene, toluene, benzyl and veratryl alcohol as well as oxidizes typical peroxidase substrates such as ABTS and DMP (but neither chloride nor bromide). The fungus produced up to $41.000 \mathrm{U} \mathrm{L}^{-1}\left(445 \mathrm{mg} \mathrm{L}^{-1}\right)$ of MroAPO in a complex medium rich in organic carbon and nitrogen $(4.2 \%$ glucose, $4.5 \%$ soybean peptone and $0.45 \%$ yeast extract). To our best knowledge, the calculated amount of $445 \mathrm{mg} \mathrm{L}^{-}$ ${ }^{1}$ peroxygenase protein is one of the highest levels of a secreted heme peroxidase reported for a wild-type basidiomycete so far.

Interestingly, culturing the known peroxygenase producers $A$. aegerita and $C$. radians in the same complex medium did neither promote growth nor enzyme secretion (Gröbe 2011, unpublished result). A. aegerita was the first APO producer described and found to secrete appreciable levels of the enzyme, AaeAPO ${ }^{\mathrm{a}}$, merely in the presence of soybean meal (Ullrich et al. 2004). The best result, 2,021 U L $\mathrm{U}^{-1}$ corresponding to $12 \mathrm{mg} \mathrm{L}^{-1}$ APO protein, was reported for an agitated slurry-culture containing $60 \mathrm{~g} \mathrm{~L}^{-1}$ soybean meal. However, due to the high particle density, usually lower amounts of soybean meal $\left(20 \mathrm{~g} \mathrm{~L}^{-1}\right)$ have been used to produce AaeAPO in stirred-tank bioreactors with activity levels of 500 to 1,500 $\mathrm{U} \mathrm{L}^{-1}$ (2.5-10 $\left.\mathrm{mg} \mathrm{L}^{-1}\right)$ (Ullrich et al. 2004,, Ullrich et al. 2009). The second APO producer, C. radians, secreted $176 \mathrm{U} \mathrm{L}^{-1}\left(4.5 \mathrm{mg} \mathrm{L}^{-1}\right)$ in a similar soybean medium (Anh et al. 2007). As in case of MroAPO, supplementation of this medium with glucose was found to further stimulate $\mathrm{CraAPO}$ production; the best result (277 $\mathrm{U} \mathrm{L}^{-1}, \sim 7 \mathrm{mg} \mathrm{L}^{-1}$ ) was obtained when $3 \%$ soybean meal and $4 \%$ glucose were used (Anh et al. 2007). Using C. fumago in a semi-continuous flow bioreactor, levels of $C f u C P O$ greater than $600 \mathrm{mg} \mathrm{L}^{-1}$ (maximum level in one occasion 1,083 $\mathrm{mg} \mathrm{L}^{-1}$ ) were obtained in a synthetic medium based on glucose as carbon source (Blanke et al. 1989). Batch fermentation of the same fungus in an optimized fructose-based medium resulted in $\mathrm{CfuCPO}$ levels of up to $450 \mathrm{mg} \mathrm{L}^{-1}$ (Carmichael and Pickard 1989). The maximum MroAPO levels reported here are in the same order of magnitude (up to $445 \mathrm{mg} \mathrm{L}^{-1}$ in culture flasks, and $280 \mathrm{mg} \mathrm{L}^{-1}$ in stirred-tank bioreactors), which is remarkable, since $M$. rotula is an agaric basidiomycete (known to be sensitive and slowly growing; Ullrich et al. 2004,, Tang et al. 2007), whereas C. fumago is a fast growing ascomycete (sooty mold). To summarize, protein yields of heme-thiolate peroxidases follow this order:

$$
\mathrm{Cfu} \mathrm{CPO} \approx \mathrm{MroAPO}>>\text { AaeAPO }>\mathrm{CraAPO}
$$

Production of a classic peroxidase (EC 1.11.1.7) by Coprinopsis (Coprinus) cinerea UAMH 4103 in a similar complex medium (2.9\% glucose, $1.4 \%$ peptone, $0.3 \%$ yeast extract, $0.3 \%$ malt extract) resulted in activities up to $68,000 \mathrm{U} \mathrm{L}^{-1}$ (determined with a colorimetric assay using phenol and 4-aminoantipyrine, and corresponding to $155 \mathrm{mg} \mathrm{L}^{-1}$ protein; Ikehata et al. 2004,, Ikehata et al. 2005).

With a molecular mass of $32 \mathrm{kDa}$, MroAPO is considerably (by 10-40\%) smaller than other fungal heme-peroxidases including APOs (43-46 kDa) and CfuCPO (4046 kDa) (Hatakka 1994, Hofrichter et al. 2010).

Table 2 Spectral characteristics of MroAPO in comparison to respective data of two other APOs, CPO and a P450 monooxygenase (Hofrichter and Ullrich 2006,, Anh et al. 2007,, Faber et al. 2001)

\begin{tabular}{|c|c|c|c|c|c|c|c|}
\hline \multirow[t]{2}{*}{ Organism } & \multirow[t]{2}{*}{ Enzyme } & \multicolumn{3}{|c|}{ Soret maxima $(\mathrm{nm})$} & \multicolumn{3}{|c|}{ Further maxima of the resting enzyme } \\
\hline & & Resting & Reduced & CO adduct & $\alpha$ & $\beta$ & $\delta$ \\
\hline Marasmius rotula & MroAPO & 418 & 418 & 443 & 570 & 536 & 353 \\
\hline Agrocybe aegerita & AaeAPO & 420 & 413 & 447 & 572 & 540 & 359 \\
\hline Coprinus radians & CraAPO & 422 & 426 & 446 & 571 & 542 & 359 \\
\hline Caldariomyces fumago & $\mathrm{CPO}$ & 401 & 409 & 443 & - & 545 & - \\
\hline Aspergillus niger & CYP53A1 & 418 & n.d. & 448 & 568 & 538 & 361 \\
\hline
\end{tabular}




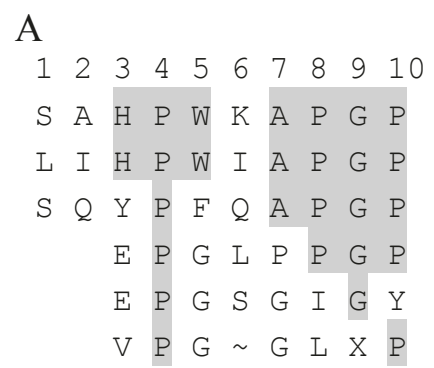

\author{
Marasmius rotula (MroAPO) \\ Talaromyces stipitatus (putative protein, B8LZ19) \\ Moniliophthora perniciosa (putative protein, E2LMD4) \\ Agrocybe aegerita (AaeAPO; B9W4V6) \\ Caldariomyces fumago (CfuCPO; $\mathrm{P} 04963)$ \\ Coprinellus radians (CraAPO; B9W4V8)
}

\section{Moniliophthora perniciosa (putative protein, E2LMD4) \\ $M$. rotula de-novo peptide sequence (1443.64 Da)}

Figure $5 \mathrm{~N}$-terminal sequences (A) and peptide fragment alignment (B) of MroAPO, AaeAPO, CraAPO and CfuCPO as well as hypothetical APO-like sequences. UniProt protein sequence accessions are given in brackets.

Furthermore MroAPO is less glycosylated (16\%) than the other heme-thiolate peroxidases (CraAPO 37\%, AaeAPO 20\%, CPO 25-30\%). The determined isoelectric points of MroAPO varied between 4.97 and 5.27 (major band at 5.27) indicating the presence of several similar isoforms. Isoforms with the same molecular mass but slightly different, acidic pIs were also reported for AaeAPO (4.6-5.6, Ullrich et al. 2004,; 5.2-6.1, Ullrich et al. 2009) and CraAPO (3.8-4.2, Anh et al. 2007).

The UV-Vis absorption spectrum of MroAPO showed a characteristic shift of the Soret band from $418 \mathrm{~nm}$ to $443 \mathrm{~nm}$ after reduction and CO-treatment. The shift of the CO-complex' Soret band towards $450 \mathrm{~nm}$ is characteristic for all heme-thiolate enzymes (Omura 2005), including APOs, CfuCPO and P450s.

A distinctive catalytic feature of MroAPO is the limited halide oxidation (restricted to iodide) and hence the lacking of brominating or chlorinating activities. In contrast, AaeAPO and CraAPO can efficiently oxidize bromide and $C f u C P O$ in addition chloride (Hofrichter and Ullrich 2006), i.e. halide oxidation by heme-thiolate peroxidases follows this order:

$$
\mathrm{C} f u \mathrm{CPO}>>\mathrm{A} a e \mathrm{APO} \approx \mathrm{CraAPO}>\mathrm{MroAPO}
$$

On the other hand, the catalytic activities of MroAPO towards classic peroxidase substrates such as ABTS and DMP as well as the peroxygenation of aryl alcohols resemble reactions catalyzed by the three other hemethiolate peroxidases (AaeAPO, CraAPO and CfuCPO; Ullrich et al. 2004,, Anh et al. 2007,, Baciocchi et al. 2001). Unlike $C f u C P O$ - but in accordance with AaeAPO and CraAPO - MroAPO was found to hydroxylate naphthalene and the aromatic ring of toluene (Zaks and Dodds 1995,, Ullrich and Hofrichter 2005,, Anh et al. 2007,), and thus its classification as APO is justifiable (Hofrichter et al. 2010). Naphthalene hydroxylation by MroAPO is about 10-times less efficient than by AaeAPO but comparable to CraAPO (Kluge et al. 2007,, Anh et al. 2007). In case of toluene conversion by MroAPO, the observed ratio of ring vs. methyl group oxidation of $26: 1$ is considerably higher than that of AaeAPO (2:1; Ullrich et al. 2009) and points to a preference of alkyl side-chains (e.g. benzylic carbon) over aromatic rings in peroxygenation reactions. A similar preference of non-aromatic carbon was observed for methylnaphthalenes and fluorene oxidation by $\mathrm{CraAPO}$ while AaeAPO again primarily hydroxylated the aromatic rings (Aranda et al. 2010). In summary, the oxygen transfer potential of heme-thiolate peroxidases can be arranged in the following order:

$$
\text { AaeAPO }>\mathrm{CraAPO} \approx \mathrm{MroAPO}>C f u \mathrm{CPO}
$$

The optimum $\mathrm{H}_{2} \mathrm{O}_{2}$ concentration for the oxidation of veratryl alcohol by MroAPO was $4 \mathrm{mM}$ (for benzyl alcohol even $>10 \mathrm{mM}$ ), which clearly exceeds the values reported for CraAPO (0.5-0.7 mM) and AaeAPO (2 $\mathrm{mM}$ ) (Anh et al. 2007,, Ullrich et al. 2004). This fact is also reflected by a 2-3 times lower affinity of MroAPO to $\mathrm{H}_{2} \mathrm{O}_{2}\left(\mathrm{~K}_{\mathrm{m}}: 3.1 \mathrm{mM}\right)$ and implies a generally higher peroxide demand that may be caused by a pseudo-catalase activity. On the other hand, this $K_{m}$ is in the same order of magnitude as the values for AaeAPO and CraAPO (1.3 and $1.2 \mathrm{mM}$, respectively; Ullrich et al. 2004,, Anh et al. 2007). MroAPO was found to be active in a wide $\mathrm{pH}$ range between 2 and 9. This behavior generally resembles AaeAPO and CraAPO, but unlike the latter, MroAPO did not show a neutral but an acidic pH optimum (between 5.5 and 6) in case of naphthalene hydroxylation (Kluge et al. 2007,, Anh et al. 2007).

MroAPO is the third aromatic/unspecific peroxygenase that has been characterized. Concerning its most relevant catalytic property - the transfer of peroxide- 


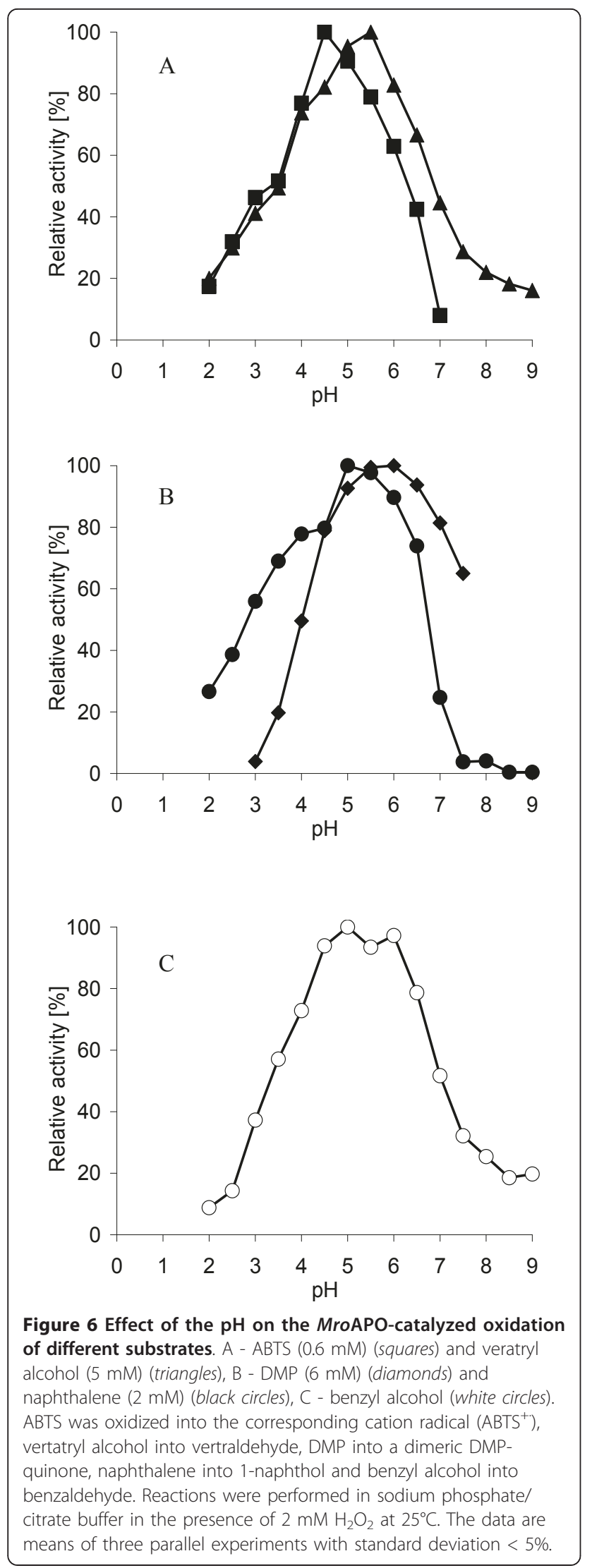

Table 3 Apparent kinetic parameters of purified MroAPO

\begin{tabular}{ccccc}
\hline Substrate & $\mathbf{p H}$ & $\begin{array}{c}\mathbf{K}_{\mathbf{m}} \\
(\mathbf{m M})\end{array}$ & $\begin{array}{c}\mathbf{k}_{\text {cat }} \\
\left(\mathbf{s}^{-1}\right)\end{array}$ & $\begin{array}{c}\mathbf{k}_{\mathbf{c a t}} / \mathbf{K}_{\mathbf{m}} \\
\left(\mathbf{s}^{-1} \mathbf{M}^{-1}\right)\end{array}$ \\
\hline ABTS & 4.5 & 0.071 & 25 & $3,53^{*} 10^{5}$ \\
DMP & 5.5 & 0.133 & 70 & $5.29^{*} 10^{5}$ \\
Benzyl alcohol & 5.5 & 0.118 & 62 & $5.29^{*} 10^{5}$ \\
Veratryl alcohol & 5.5 & 0.279 & 49 & $1.76^{*} 10^{5}$ \\
Naphthalene & 5.5 & 0.791 & 33 & $4.25^{*} 10^{4}$ \\
$\mathrm{H}_{2} \mathrm{O}_{2}$ & 5.5 & 3.14 & 76 & $2.42^{*} 10^{4}$ \\
\hline
\end{tabular}

Reactions were performed in sodium phosphate/citrate buffer ( $\mathrm{pH} 4.5$ or 5.5) in the presence of $2 \mathrm{mM} \mathrm{H}_{2} \mathrm{O}_{2}$ at $25^{\circ} \mathrm{C}$. The $\mathrm{K}_{\mathrm{m}}$ for the co-substrate $\mathrm{H}_{2} \mathrm{O}_{2}$ was determined in the presence of $5 \mathrm{mM}$ veratryl alcohol. The data are means of three parallel experiments with standard deviation $<5 \%$.

borne oxygen to non-activated carbon - it ranges, together with CraAPO, between AaeAPO and CfuCPO. The high stability towards $\mathrm{pH}$ and organic solvents as well as the possibility to "naturally over-express" MroAPO, i.e. to obtain enzyme yields of several hundred $\mathrm{mg} \mathrm{L}^{-1}$ using a wild-type strain, makes the enzyme and the fungus promising targets of further bioengineering and molecular studies, for example, regarding peroxygenase production at larger scale, promotor analysis and heterologous expression of low-yield peroxygenases from other basidiomycetes.

\section{Endnotes}

${ }^{a}$ In earlier publications, the enzyme was abbreviated AaP (Agrocybe aegerita peroxidase/peroxygenase; Ullrich et al. 2004,, Hofrichter and Ullrich 2006)

\section{Acknowledgements}

Financial support by the European Union (integrated projects BIORENEW, PEROXICATS), the Bundesministerium für Bildung, Wissenschaft und Forschung (BMBF, Cluster Integrierte Bioindustrie Frankfurt), and the Deutsche Bundesstiftung Umwelt (project "Neuartige Peroxygenasen") is gratefully acknowledged. We thank T. Koncz, M. Kluge, M. Brandt for useful discussions and technical assistance.

\section{Author details}

'Department of Biology, Chemistry and Process Technology, Lausitz University of Applied Sciences, Großenhainer Straße 57, 01968 Senftenberg, Germany ${ }^{2}$ Department of Environmental Biotechnology, Department of Bioand Environmental Sciences, International Graduate School of Zittau, Markt 23, 02763 Zittau, Germany ${ }^{3}$ Department of Soil Ecology, Helmholtz Centre for Environmental Research - UFZ Halle, Theodor-Lieser-Straße 4, 06120

Halle/Saale, Germany ${ }^{4}$ JenaBios GmbH, Orlaweg 2, 07743 Jena, Germany

\section{Competing interests}

The authors declare that they have no competing interests.

Received: 6 May 2011 Accepted: 11 October 2011

Published: 11 October 2011

\section{References}

Anh DH, Ullrich R, Benndorf D, Svatos A, Muck A, Hofrichter M (2007) The coprophilous mushroom Coprinus radians secretes a haloperoxidase that catalyzes aromatic peroxygenation. Appl Environ Microbiol 73:5477-5485. doi:10.1128/AEM.00026-07.

Aranda E, Kinne M, Kluge M, Ullrich R, Hofrichter M (2009) Conversion of dibenzothiophene by the mushrooms Agrocybe aegerita and Coprinellus 
radians and their extracellular peroxygenases. Appl Microbiol Biotechnol 82:1057-1066. doi:10.1007/s00253-008-1778-6.

Aranda E, Ullrich R, Hofrichter M (2010) Conversion of polycyclic aromatic hydrocarbons, methyl naphthalenes and dibenzofuran by two fungal peroxygenases. Biodegradation 21:267-281. doi:10.1007/s10532-009-9299-2.

Baciocchi E, Fabbrini M, Lanzalunga O, Manduchi L, Pochetti G (2001) Prochiral selectivity in $\mathrm{H}(2) \mathrm{O}(2)$-promoted oxidation of arylalkanols catalysed by chloroperoxidase. The role of the interactions between the $\mathrm{OH}$ group and the amino-acid residues in the enzyme active site. Eur J Biochem 268:665-672. doi:10.1046/j.1432-1327.2001.01924.x.

Blanke SR, Yi S, Hager LP (1989) Development of semi-continuous and continuous flow bioreactors for the high level production of chloroperoxidase. Biotechnol Lett 11:769-774. doi:10.1007/BF01026094.

Carmichael RD, Pickard MA (1989) Continuous and batch production of chloroperoxidase by mycelial pellets of Caldariomyces fumago in an airlift fermentor. Appl Environ Microbiol 55:17-20.

Celio GJ, Padamsee M, Dentinger BT, Bauer R, McLaughlin DJ (2006) Assembling the Fungal Tree of Life: constructing the structural and biochemical database. Mycologia 98(6):850-9. doi:10.3852/mycologia.98.6.850.

Faber BW, van Gorcom RF, Duine JA (2001) Purification and characterization of benzoate-para-hydroxylase, a cytochrome P450 (CYP53A1), from Aspergillus niger. Arch Biochem Biophys 394:245-254. doi:10.1006/abbi.2001.2534.

Hall TA (1999) BioEdit: a user-friendly biological sequence alignment editor and analysis program for Windows 95/98/NT. Nucl Acids Symp Ser 41:95-98

Hatakka A (1994) Lignin-modifying enzymes from selected white-rot fungi: production and role from in lignin degradation. FEMS Microbiol Rev 13:125-135. doi:10.1111/j.1574-6976.1994.tb00039.x.

Hofrichter M, Ullrich R (2006) Heme-thiolate haloperoxidases: versatile biocatalysts with biotechnological and environmental significance. Appl Microbiol Biotechnol 71:276-288. doi:10.1007/s00253-006-0417-3.

Hofrichter M, Ullrich R, Pecyna M, C L, Lundell T (2010) New and classic families of secreted fungal heme peroxidases. Appl Microbiol Biotechnol 87:871-897. doi:10.1007/s00253-010-2633-0.

Ikehata K, Buchanan ID, Pickard MA, Smith DW (2005) Purification, characterization and evaluation of extracellular peroxidase from two Coprinus species for aqueous phenol treatment. Bioresour Technol 96:1758-1770. doi:10.1016/j.biortech.2005.01.019.

Ikehata K, Pickard MA, Buchanan ID, Smith DW (2004) Optimization of extracellular fungal peroxidase production by 2 Coprinus species. Can J Microbiol 50:1033-1040. doi:10.1139/w04-098.

Joo H, Lin Z, Arnold FH (1999) Laboratory evolution of peroxide-mediated cytochrome P450 hydroxylation. Nature 399:670-673. doi:10.1038/21395.

Kerekes JF, Desjardin DE (2009) A monograph of the genera Crinipellis and Moniliophthora from Southeast Asia including a molecular phylogeny of the nrlTS region. Fungal Diversity 37:101-152.

Kinne M, Poraj-Kobielska M, Ralph SA, Ullrich R, Hofrichter M, Hammel KE (2009) Oxidative cleavage of diverse ethers by an extracellular fungal peroxygenase. J Biol Chem 284:29343-9. doi:10.1074/jbc.M109.040857.

Kluge MG, Ullrich R, Scheibner K, Hofrichter M (2007) Spectrophotometric assay for detection of aromatic hydroxylation catalyzed by fungal haloperoxidaseperoxygenase. Appl Microbiol Biotechnol 75:1473-1478. doi:10.1007/s00253007-0942-8.

Libby RD, Thomas JA, Kaiser LW, Hager LP (1982) Chloroperoxidase halogenation reactions. Chemical versus enzymic halogenating intermediates. J Biol Chem 257:5030-5037

Majcherczyk A, Johannes C, Hüttermann A (1999) Oxidation of aromatic alcohols by laccase from Trametes versicolor mediated by the 2,2'-azino-bis-(3ethylbenzothiazoline-6-sulphonic acid) cation radical and dication. Appl Microbiol Biotechnol 51:267-276. doi:10.1007/s002530051392.

McCarthy MB, White RE (1983) Functional differences between peroxidase compound I and the cytochrome P-450 reactive oxygen intermediate. J Biol Chem 258:9153-9158.

Omura T (2005) Heme-thiolate proteins. Biochem Biophys Res Commun 338:404-409. doi:10.1016/j.bbrc.2005.08.267.

Pecyna MJ, Ullrich R, Bittner B, Clemens A, Scheibner K, Schubert R, Hofrichter M (2009) Molecular characterization of aromatic peroxygenase from Agrocybe aegerita. Appl Microbiol Biotechnol 84:885-897. doi:10.1007/s00253-009-2000-1.

Pickard MA, Kadima TA, Carmichael RD (1991) Chloroperoxidase, a peroxidase with potential. Journal Industrial Microbiol Biotechnol 7:235-241.
Smith GC, Tew DG, Wolf CR (1994) Dissection of NADPH-cytochrome P450 oxidoreductase into distinct functional domains. Proc Natl Acad Sci USA 91:8710-8714. doi:10.1073/pnas.91.18.8710.

Tang Y-J, Zhu L-W, Li H-M, Li D-S (2007) Submerged Culture of Mushrooms in Bioreactors - Challenges, Current State-of-the-Art, and Future Prospects. Food Technol Biotechnol 45:221-229.

Ullrich R, Hofrichter M (2005) The haloperoxidase of the agaric fungus Agrocybe aegerita hydroxylates toluene and naphthalene. FEBS Lett 579:6247-6250. doi:10.1016/j.febslet.2005.10.014.

Ullrich R, Liers C, Schimpke S, Hofrichter M (2009) Purification of homogeneous forms of fungal peroxygenase. Biotechnol J 4:1619-1626. doi:10.1002/ biot.200900076.

Ullrich R, Nuske J, Scheibner K, Spantzel J, Hofrichter M (2004) Novel haloperoxidase from the agaric basidiomycete Agrocybe aegerita oxidizes aryl alcohols and aldehydes. Appl Environ Microbiol 70:4575-4581. doi:10.1128/ AEM.70.8.4575-4581.2004.

Urlacher VB, Eiben S (2006) Cytochrome P450 monooxygenases: perspectives for synthetic application. Trends Biotechnol 24:324-330. doi:10.1016/j. tibtech.2006.05.002.

Urlacher VB, Lutz-Wahl S, Schmid RD (2004) Microbial P450 enzymes in biotechnology. Appl Microbiol Biotechnol 64:317-325. doi:10.1007/s00253003-1514-1.

White TJ, Bruns T, Lee S, Taylor JW (1990) Amplification and direct sequencing of fungal ribosomal RNA genes for phylogenetics. PCR Protocols: A Guide to Methods and Applications. Academic Press, Inc., New York pp 315-322

Zhang Z, Schwartz S, Wagner L, Miller W (2000) A greedy algorithm for aligning DNA sequences. J Comput Biol 7(1-2):203-14. doi:10.1089/ 10665270050081478.

Zaks A, Dodds DR (1995) Chloroperoxidase-catalyzed asymmetric oxidations: substrate specificity and mechanistic study. J Am Chem Soc 117:10419-10424. doi:10.1021/ja00147a001.

doi:10.1186/2191-0855-1-31

Cite this article as: Gröbe et al:: High-yield production of aromatic peroxygenase by the agaric fungus Marasmius rotula. AMB Express 2011 1:31.

\section{Submit your manuscript to a SpringerOpen ${ }^{\mathcal{O}}$ journal and benefit from:}

- Convenient online submission

- Rigorous peer review

- Immediate publication on acceptance

- Open access: articles freely available online

- High visibility within the field

- Retaining the copyright to your article

Submit your next manuscript at $\gg$ springeropen.com 